\title{
How Do We Improve the Utility of Fractional Flow Reserve? - For Precise Diagnosis of Myocardial Ischemia -
}

\author{
Hideki Ishii, MD, PhD; Toyoaki Murohara, MD, $\mathrm{PhD}$
}

0 tudies have suggested that the benefit of percutaneous coronary intervention (PCI) is less clear in lesions without evidence of myocardial ischemia, compared with medical therapy alone, although the benefit of PCI is significant in coronary lesions related to a large risk area $(>10 \%) .{ }^{1}$ In such situations, physiological examinations to prove myocardial ischemia has been recently recommended to perform coronary revascularization. ${ }^{2}$ Fractional flow reserve (FFR) is very useful for detecting myocardial ischemia and FFR-guided PCI is an option to assess the physiological significance of coronary stenosis. ${ }^{3-5}$

Unfortunately, uncertain results of FFR may lead to an inappropriate judgement, so confirmation of the certainty of the FFR value is essential. To obtain a reliable FFR measurement, optimal hyperemia must be induced to avoid the effect of microvascular resistance. ${ }^{6}$ In the clinical setting, either continuous intravenous administration of adenosine

\begin{tabular}{l} 
Article p 2010 \\
\hline triphosphate (ATP) $(150-180 \mu \mathrm{g} / \mathrm{kg} / \mathrm{min})$ via the forearm or \\
femoral vein, or intracoronary injection of ATP $(40-80 \mu \mathrm{g})$ \\
are the current standard methods of achieving maximal \\
coronary hyperemia. ${ }^{7}$ Because ATP has several advantages, \\
such as short duration of action, it is widely used, but it \\
can also induce atrioventricular (AV) conduction delay, \\
ventricular arrhythmia and dyspnea caused by bronchial \\
hyper-reactivity. ${ }^{8}$ Moreover, we may sometimes miss a \\
caffeine attenuated adenosine-induced hyperemic response \\
caused by blocking of adenosine receptor activity.9 \\
Other disadvantages of FFR include a significantly longer \\
procedural time and increased vasodilator side-effects of \\
using agents for hyperemia, compared with resting indexes \\
such as the instant wave-free ratio. In this issue of the
\end{tabular}

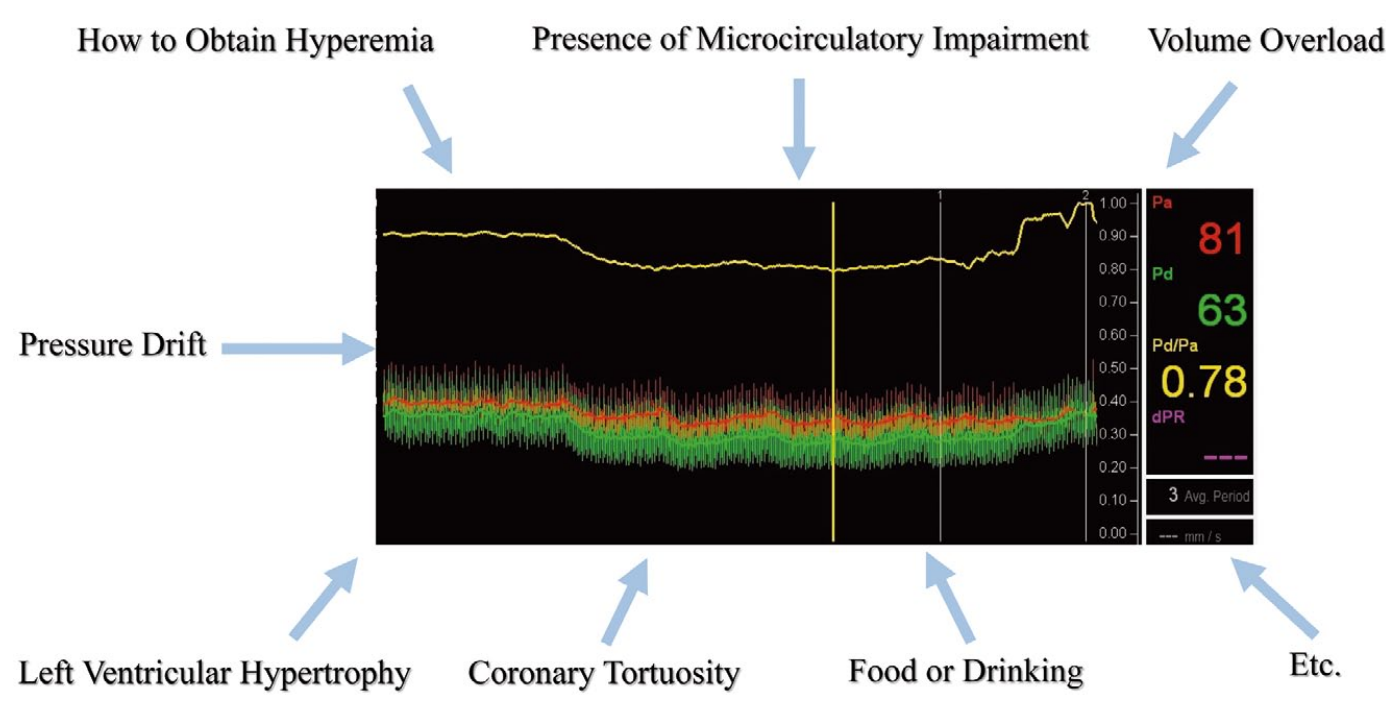

Figure. Various factors affecting measurement of fractional flow reserve (FFR) that need to be considered in order to achieve a precise FFR value.

The opinions expressed in this article are not necessarily those of the editors or of the Japanese Circulation Society.

Received August 7, 2019; accepted August 24, 2019; J-STAGE Advance Publication released online September 3, 2019

Department of Cardiology, Nagoya University Graduate School of Medicine, Nagoya, Japan

The Guest Editor for this article was Dr. Yoshihiko Saito.

Mailing address: Hideki Ishii, MD, PhD, Department of Cardiology, Nagoya University Graduate School of Medicine, 65

Tsurumai-cho, Showa-ku, Nagoya 466-8560, Japan. E-mail: hkishii@med.nagoya-u.ac.jp

ISSN-1346-9843 All rights are reserved to the Japanese Circulation Society. For permissions, please e-mail: cj@j-circ.or.jp 
Journal, Ishibuchi et $\mathrm{al}^{10}$ report that intracoronary administration of $2 \mathrm{mg}$ nicorandil produced a more pronounced hyperemia during FFR measurement, compared with continuous intravenous ATP. In Japan and Korea, injectable nicorandil has been widely used as treatment for ischemic heart disease, ${ }^{11}$ so it is well known that the technique is simple, with relatively short injection time, and safe, without major complications. Previous reports have already suggested that intracoronary bolus injection of nicorandil can achieve steady-state hyperemia during assessment of FFR. ${ }^{12,13}$ Another study has reported that the plateau time of intracoronary 2-mg doses of nicorandil is approximately $26 \mathrm{~s},{ }^{12}$ which is sufficient to measure FFR in pressure pullback tracings. However, more importantly, the present study suggests that intravenous ATP infusion at $150 \mu \mathrm{g} / \mathrm{kg} / \mathrm{min}$ for $2 \mathrm{~min}$, which is used in clinical practice, achieves maximum hyperemia in only $54 \%$ of cases. As maximal coronary hyperemia is needed for reliable FFR measurement, these findings have clinical significance.

As well as adequate hyperemia, various aspects that may be missing in daily practice should be reconsidered to obtain precise values of FFR (Figure). First, FFR is usually calculated as the mean coronary blood pressure distal to the stenosis divided by the mean aortic pressure without accounting for mean right central venous pressure. Therefore, precise evaluation may not be obtained in patients with high venous pressure, such as those on hemodialysis. Second, pressure drift might be induced by body temperature as well as disconnecting and reconnecting the wire from the connector. Third, valvular heart disease such as aortic valve stenosis affects coronary circulation. ${ }^{14}$ Fourth, increased microvascular resistance, which is seen in old myocardial infarction, may increase FFR because of impairment of hyperemic coronary flow, which limits maximal and constant vasodilation. ${ }^{15}$ In such cases, significant ischemia may be underestimated. Therefore, we should take these factors into consideration to avoid "white noise".

In conclusion, physiological assessments such as FFR are very important for diagnosing myocardial ischemia and determining coronary revascularization with $\mathrm{PCI}$ or $\mathrm{CABG}$. However, there are some pitfalls in FFR measurement, as mentioned above. We have to pay attention to obtaining a precise diagnosis of myocardial ischemia and do everything to improve the utility of FFR.

\section{Disclosures}

H. Ishii received lecture fees from Astellas Pharma Inc., Astrazeneca Inc., Bayer Pharmaceutical Co., Ltd., Bristol-Myers Squibb Inc., Chugai Pharmaceutical Co., Ltd., Daiichi-Sankyo Pharma Inc., and MSD K.K. T. Murohara received lecture fees from Bayer Pharmaceutical Co., Ltd., Daiichi-Sankyo Co., Ltd., Dainippon Sumitomo Pharma Co., Ltd., Kowa Co., Ltd., MSD K.K., Mitsubishi Tanabe Pharma Co., Nippon Boehringer Ingelheim Co., Ltd., Novartis Pharma K.K., Pfizer Japan Inc., Sanofi-aventis K.K., and Takeda Pharmaceutical Co., Ltd. T. Murohara received unrestricted research grant for Department of Cardiology, Nagoya University Graduate School of Medicine from Astellas Pharma Inc., Daiichi-Sankyo Co., Ltd., Dainippon Sumitomo Pharma Co., Ltd., Kowa Co., Ltd., MSD K.K., Mitsubishi Tanabe Pharma Co., Nippon Boehringer Ingelheim Co., Ltd., Novartis Pharma K.K., Otsuka Pharma Ltd., Pfizer Japan
Inc., Sanofi-aventis K.K., Takeda Pharmaceutical Co., Ltd., and Teijin Pharma Ltd.

\section{References}

1. Hachamovitch R, Hayes SW, Friedman JD, Cohen I, Berman DS. Comparison of the short-term survival benefit associated with revascularization compared with medical therapy in patients with no prior coronary artery disease undergoing stress myocardial perfusion single photon emission computed tomography. Circulation 2003; 107: 2900-2907.

2. Neumann FJ, Sousa-Uva M, Ahlsson A, Alfonso F, Banning AP, Benedetto U, et al. 2018 ESC/EACTS Guidelines on myocardial revascularization. Eur Heart $J$ 2019; 40: 87-165.

3. Pijls NH, Van Gelder B, Van der Voort P, Peels K, Bracke FA, Bonnier HJ, et al. Fractional flow reserve: A useful index to evaluate the influence of an epicardial coronary stenosis on myocardial blood flow. Circulation 1995; 92: 3183-3193.

4. Arashi H, Yamaguchi J, Nakazawa M, Otsuki H, Haruki S, Nakao M, et al. Lesion characteristics of coronary arteries associated with a mismatch between angiographic severity of stenosis and fractional flow reserve. Cardiovasc Interv Ther 2017; 32: $120-126$.

5. Tanaka N, Nakamura M, Akasaka T, Kadota K, Uemura S, Amano T, et al. One-year outcome of fractional flow reserve-based coronary intervention in Japanese daily practice: CVIT-DEFER registry. Circ J 2017; 81: 1301-1306.

6. Pijls NH, van Son JA, Kirkeeide RL, De Bruyne B, Gould KL. Experimental basis of determining maximum coronary, myocardial, and collateral blood flow by pressure measurements for assessing functional stenosis severity before and after percutaneous transluminal coronary angioplasty. Circulation 1993; 87: 13541367.

7. De Bruyne B, Pijls NH, Barbato E, Bartunek J, Bech JW, Wijns W, et al. Intracoronary and intravenous adenosine 5'-triphosphate, adenosine, papaverine, and contrast medium to assess fractional flow reserve in humans. Circulation 2003; 107: 1877-1883.

8. Patel HR, Shah P, Bajaj S, Virk H, Bikkina M, Shamoon F. Intracoronary adenosine-induced ventricular arrhythmias during fractional flow reserve (FFR) measurement: Case series and literature review. Cardiovasc Interv Ther 2017; 32: 374-380.

9. Matsumoto H, Nakatsuma K, Shimada T, Ushimaru S, Mikuri M, Yamazaki T, et al. Effect of caffeine on intravenous adenosineinduced hyperemia in fractional flow reserve measurement. $J$ Invasive Cardiol 2014; 26: 580-585.

10. Ishibuchi K, Fujii K, Otsuji S, Takiuchi S, Hasegawa K, Tamaru $\mathrm{H}$, et al. Utility and validity of intracoronary administration of nicorandil alone for the measurement of fractional flow reserve in patients with intermediate coronary stenosis. Circ J 2019; 83: $2010-2016$.

11. Ishii H, Amano T, Matsubara T, Murohara T. Pharmacological intervention for prevention of left ventricular remodeling and improving prognosis in myocardial infarction. Circulation 2008; 118: $2710-2718$.

12. Jang HJ, Koo BK, Lee HS, Park JB, Kim JH, Seo MK, et al. Safety and efficacy of a novel hyperaemic agent, intracoronary nicorandil, for invasive physiological assessments in the cardiac catheterization laboratory. Eur Heart J 2013; 34: 2055-2062.

13. Oi M, Toyofuku M, Matsumura Y, Motohashi Y, Takahashi K, Kawase Y, et al. Utility of nicorandil for the measurement of coronary fractional flow reserve. Cardiovasc Interv Ther 2014; 29: 24-30.

14. Pesarini G, Scarsini R, Zivelonghi C, Piccoli A, Gambaro A, Gottin L, et al. Functional assessment of coronary artery disease in patients undergoing transcatheter aortic valve implantation: Influence of pressure overload on the evaluation of lesions severity. Circ Cardiovasc Interv 2016; 9: pii: e004088.

15. Emori H, Kubo T, Kameyama T, Ino Y, Matsuo Y, Kitabata H, et al. Diagnostic accuracy of quantitative flow ratio for assessing myocardial ischemia in prior myocardial infarction. Circ J 2018; 82: $807-814$. 